\title{
Lipid production and heavy metals adsorption by an Aspergillus fumigatus GAH1 isolate
}

\author{
Ahmed M. Haddad *, Hadeel S. El-Shall, Gadallah Abu-Elreesh \\ Environmental Biotechnology Department, Genetic Engineering and Biotechnology Research Institute, \\ City of Scientific Research and Technological Applications, Alexandria, Egypt
}

\begin{abstract}
Few species of filamentous fungi can accumulate considerable amounts of intracellular lipids when grown under certain stress conditions; thus, they can be used for biodiesel production. Moreover, their residual biomass can be used for the removal of heavy metals from contaminated water. An oleaginous Aspergillus fumigatus GAH1 isolate was isolated from a soil sample in Borg El-Arab industrial area, Alexandria, Egypt, and was characterized in batch cultures. The influence of different carbon and nitrogen sources and the initial $\mathrm{pH}$ of the medium on the fungal biomass and lipid production was investigated. Under optimized conditions, the A. fumigatus GAH1 isolate could accumulate up to $22.4 \%$ of its dry biomass as lipids. Oleic and palmitic acids were the dominant fatty acid fractions produced. After lipid extraction, to further improve the process economy, the fungal biomass was applied as a biosorbent to remove heavy metals such as $\mathrm{Cr}, \mathrm{Cd}$, and $\mathrm{Zn}$ from contaminated wastewater. The biosorption efficiency and capacity of the raw, $\mathrm{H}_{2} \mathrm{O}$-washed, and $\mathrm{NaOH}$-treated fungal biomass were examined. The biosorption capacity of 33.37, 29.29, and $27.75 \mathrm{mg} / \mathrm{g}$ was recorded for $\mathrm{Cr}, \mathrm{Cd}$, and $\mathrm{Zn}$, respectively. Moreover, the biosorption efficiency was more than $69 \%$ for the tested heavy metals. In conclusion, $A$. fumigatus GAH1 may be considered as a promising biodiesel producer, and its biomass waste can be further used for the biosorption of heavy metals from contaminated wastewater.
\end{abstract}

Key words: lipids, biodiesel, fungi, Aspergillus, bioremediation, heavy metals

\section{Introduction}

Because of the depletion of fossil fuel reserves and a constant increase in energy demand, researchers have become increasingly interested to find alternative renewable and sustainable fuels such as bioethanol and biodiesel (Chi et al., 2007; Amin, 2009; Singh et al., 2011; Rawat et al., 2013). Biodiesel is an important renewable biofuel that can be produced from plant oils, animal fats, or waste cooking oils (Kulkarni and Dalai, 2006; Liang and Jiang, 2013; Kahr et al., 2015). Biodiesel is a mixture of fatty acid methyl esters (FAMEs) that are produced from a combination of triacylglycerols (TAGs) and methanol in the presence of a base or an acid catalyst. To date, most of the produced biodiesel originated from plant oils, which in turn competes with the food industry (Muniraj et al., 2013).
In the last several years, researchers are paying increasing attention to the development of microbial oils as alternative resources for biodiesel production (Liang and Jiang, 2013). Microbial oils (also called single-cell oils [SCO]) can be produced from oleaginous microorganisms such as microalgae, bacteria, yeasts, and fungi that produce and store high concentrations of intracellular lipids, up to $70 \%$ of their biomass, when grown under appropriate growth conditions (Li et al., 2008; Meng et al., 2009; Ratledge and Cohen, 2013; Kahr et al., 2015). The advantages of using SCO instead of plant oils include abundant and cheap raw materials, no competition with the food industry, rapid growth, independence from season and climate, no need for land cultivation, and ease of scale-up (Yi and Zheng, 2006; Li et al., 2011). Among the oleaginous filamentous fungi,

\footnotetext{
* Corresponding author: Environmental Biotechnology Department, Genetic Engineering and Biotechnology Research Institute, City of Scientific Research and Technological Applications, 21934 New-Burg El-Arab City, Alexandria, Egypt; e-mail: ahmedhaddad@yahoo.com
} 
Mucor circinelloides accumulates some of the highest levels of lipids in its mycelia (Vicente et al., 2009). Aspergillus oryzae can also store more than $20 \%$ of its biomass as intracellular lipids (Hui et al., 2010; Muniraj et al., 2013; Cheirsilp and Kitcha, 2015).

Increased industrial activities (such as energy and fuel production, mining, fertilizer and pesticide production, electroplating, metal surface treating, surface finishing, and leather production) using heavy metals such as copper, lead, mercury, manganese, zinc, cadmium, and many more have increased the global quantity of wastewater contaminated with heavy metals. Biological absorption is an effective technology for the removal of heavy metals (Simonescu and Ferdes, 2012; Vala and Sutariya, 2012). In this process, different microorganisms such as algae, fungi, bacteria, and yeasts that can absorb and immobilize heavy metal ions by linking them with cell walls are used (Akhtar et al., 1996; Vankar and Bajpai, 2008). The simplicity of the biological absorption makes this technique one of the best methods for removing toxic materials from the environment (Mohsenzadeh and Shahrokhi, 2014). The different biomasses that can be effectively used in absorption and bioconcentration of heavy metals include living and nonliving microbial biomass, dried brown marine algae, agricultural wastes, composite chitosan biosorbent, cellulose-based sorbents, and residual biomass produced as a waste from industrial biotechnology processes (Costa and Leite, 1991; Hussein et al, 2004; Mudhoo et al., 2012; Hamidian et al., 2016). In this context, the huge amount of fungal biomass waste resulting from several industrial biotechnology processes such as biodiesel production, brewing, biopesticide production, mushroom culture, and production of some biopharmaceuticals can be used to remove heavy metal-contaminated wastewater, which is produced from diverse industrial activities.

In the present study, an oleaginous fungal isolate Aspergillus fumigatus GAH1 that accumulates lipids at $22.4 \%$ of its dry weight and detoxifies contaminated water from heavy metals was characterized and optimized in batch cultures.

\section{Materials and methods}

\section{Isolation of fungi}

Soil samples were collected from the polluted El-Max bay and Borg El-Arab industrial area, Alexandria govern- orate, Egypt, at the depth of $10-15 \mathrm{~cm}$. All samples were transferred to sterile containers and stored refrigerated at $4{ }^{\circ} \mathrm{C}$ until use. Approximately $1 \mathrm{~g}$ of each sample was serially diluted in distilled sterile water and plated on Czapek-Dox agar plates (CDA) (g/l: sucrose $30, \mathrm{NaNO}_{3} 2$, $\mathrm{KH}_{2} \mathrm{PO}_{4} 1, \mathrm{MgSO} 4.7 \mathrm{H}_{2} \mathrm{O} 0.5, \mathrm{KCl} 0.5, \mathrm{FeCl}_{3} . \mathrm{H}_{2} \mathrm{O} 0.01$, and agar 15). The medium was supplemented with $50 \mathrm{mg} / \mathrm{l}$ Rose Bengal and $100 \mathrm{mg} / \mathrm{l}$ chloramphenicol to inhibit the growth of bacteria. The $\mathrm{pH}$ of the medium was adjusted to 6.0 before autoclaving to favor fungal growth. The inoculated plates were incubated at $30^{\circ} \mathrm{C}$ for 4 days. Colonies of pure fungal isolates were obtained by repeated subcultures on CDA plates.

\section{Screening for oleaginous fungi}

Nile Red reacts with hydrophobic compounds such as lipids and emits strong red fluorescence that can be easily detected by a fluorescence microscope. The fluorescence intensity of stained cells under UV light depends on the lipid concentration. The isolates that do not accumulate lipids are only lightly fluorescent because they contain almost no lipid granules (Greenspan et al., 1985; Kimura et al., 2004). Pre-screening for oleaginous fungi was performed using 3-day-old pure culture isolates. Fungal biomass was dark incubated with $0.5 \mathrm{ml}$ PBS solution and $0.05 \mathrm{ml}$ Nile Red solution $(25 \mu \mathrm{g}$ Nile Red/acetone $1000 \mathrm{ml}$ ) for $30 \mathrm{~min}$. Then, a thin fungal film was prepared and examined using a fluorescence microscope (IX-70, Olympus, Tokyo, Japan) equipped with a CCD camera (U-CMT, Olympus). The oleaginous fungus that gave the highest red fluorescence signal (due to the presence of oil droplets) was selected for further investigation.

\section{Morphological identification of the fungus}

The isolated fungal strain GAH1 was identified to the genus level based on the colony macromorphological characteristics (color, texture appearance, and diameter of the colonies) and micromorphological characteristics (spores, sporophore, and mycelium shape) when grown on potato dextrose agar medium. The most updated keys for identifications were used (Samson et al., 2007; Kidd et al., 2016).

\section{Biomass determination}

The fungal isolate GAH1 was cultivated in Czapek-Dox medium with an initial $\mathrm{pH}$ of 6.0. Samples were collected 
every $24 \mathrm{~h}$ for 7 days. The fungal biomass was harvested from the media by centrifugation, washed twice with distilled water to remove residual nutrients, and then freeze dried at $-50^{\circ} \mathrm{C}$. Fungal biomass was expressed as grams of dry weight per liter of culture medium.

\section{Lipid extraction}

Total lipids were extracted by grinding the fungal dry biomass in a mixture of chloroform:methanol $(2: 1)$. Ultrasonication was applied to increase cell membrane disruption during extraction. The mixture containing extracted lipids was separated from residual biomass by centrifugation at $6000 \mathrm{rpm}$ for $10 \mathrm{~min}$, and the solvent fraction was then transferred to a new tube. Then, the residual solvent was removed in a rotary evaporator followed by lyophilization to determine the ratio of extracted lipids compared to the cell dry weight (Bligh and Dyer,1959; Abu-Elreesh and Abd-El-Haleem, 2014).

\section{Transesterification of the extracted lipids}

Transesterification reaction of the extracted lipids was performed by mixing them with methanol $(30: 1$ molar ratio of methanol to oil) for $2 \mathrm{~h}$ at $70^{\circ} \mathrm{C}$ and $160 \mathrm{rpm}$ in the presence of sulfuric acid as a catalyst. After cooling the reaction mixture, it was transferred to a separating funnel for obtaining two layers: upper layer containing FAME and lower layer containing glycerol.

\section{Fatty acid profile analysis}

The FAMEs were collected and analyzed by GC/MS. The analysis was performed with Agilent $6890 \mathrm{~N}$ Gas Chromatograph connected to Agilent 5973 Mass Spectrometer at $70 \mathrm{eV}\left(\mathrm{m} / \mathrm{z} 50-550\right.$; source at $230^{\circ} \mathrm{C}$ and quadruple at $150^{\circ} \mathrm{C}$ ) in the $\mathrm{EI}$ mode with an Agilent $\mathrm{J} \& \mathrm{~W}$ HP- $5 \mathrm{~ms}$ capillary column ( $30 \mathrm{~m}, 0.25 \mathrm{~mm}$ i.d., $0.25 \mathrm{~mm}$ film thickness; J\&W Scientific, California, USA). The carrier gas helium was maintained at a flow rate of $1.0 \mathrm{ml} / \mathrm{min}$. The inlet temperature was maintained at $300^{\circ} \mathrm{C}$, and the oven was programmed for $2 \mathrm{~min}$ at $150^{\circ} \mathrm{C}$, then increased to $300^{\circ} \mathrm{C}$ at $4^{\circ} \mathrm{C} / \mathrm{min}$, and maintained for $20 \mathrm{~min}$ at $300^{\circ} \mathrm{C}$. The injection volume was $1 \mathrm{ml}$, with a split ratio of $50: 1$. Structural assignments were based on interpretation of mass spectrometric fragmentation and confirmed by comparison of retention time, fragmentation pattern of authentic compounds, and the spectral data obtained from Wiley and NIST libraries.
Optimization of biomass and lipid production by the $A$. fumigatus GAH1 isolate

Under specific culture conditions, especially in the presence of excess carbon source and limited availability of nitrogen source, oleaginous microorganisms convert diverse competitive substrates such as sugars from lignocellulose or glycerol to lipids. In the present study, one-variable-at-a-time method (OVAT) was used to investigate and optimize the biomass and lipid production of the $A$. fumigatus GAH1 isolate in response to different carbon sources (30 g/l) such as sucrose, glucose, maltose, and starch. The influence of different nitrogen sources (2 g/l) such as peptone, sodium nitrate, ammonium nitrate, potassium nitrate, and urea was examined. The effects of different initial $\mathrm{pH}$ values $(4,5,6$, and 7$)$ of the growth medium were studied. Each experiment was prepared in triplicate in $250 \mathrm{ml}$ Erlenmeyer flasks containing $50 \mathrm{ml}$ medium. After autoclaving and cooling, each flask was inoculated with a disk from the margin of 5-day-old cells on Czapek-Dox agar medium and incubated at $30^{\circ} \mathrm{C}$ for 7 days at $120 \mathrm{rpm}$. Dry biomass, lipid yield, and lipid content were determined as described above.

\section{Residual biomass of the fungal strain GAH1 as a biosorbent of heavy metals}

Chromium, cadmium, and zinc solutions were prepared at $100 \mathrm{mg} / \mathrm{l}$ concentration using anhydrous chloride salts $\left(\mathrm{CrCl}_{2}, \mathrm{CdCl}_{2}\right.$, and $\mathrm{ZnCl}_{2}$, respectively; Acros Organics, New Jersey, USA). All reagents were prepared in double distilled water. The residual fungal biomass after lipid extraction was used as a biosorbent. The harvested biomasses were used directly or after washing with double distilled water or pretreated with $\mathrm{NaOH}$ as follows: the residual fungal biomasses were slowly stirred in $0.5 \mathrm{~N} \mathrm{NaOH}$ solution for $15 \mathrm{~min}$. Then, the biomasses were washed with double distilled water till $\mathrm{pH}$ of the washing solutions became neutral (6.8-7.2); finally, the fungal biomasses were dried overnight at $60^{\circ} \mathrm{C}$, and they were then ground finely to particles with size $\leq 150 \mu \mathrm{m}$. The biosorption experiment was performed with $50 \mathrm{ml}$ of $100 \mathrm{mg} / \mathrm{l}$ initial concentrations of $\mathrm{Cr}$ (II), Cd (II), and $\mathrm{Zn}$ (II) solutions in $125 \mathrm{ml}$ flasks for $60 \mathrm{~min}$ and $150 \mathrm{rpm}$ at room temperature. After biosorption, the samples were centrifuged at $1400 \mathrm{rpm}$ for $20 \mathrm{~min}$. The residual metal ion concentrations in the supernatant were analyzed using a graphite furnace 
atomic absorption spectrophotometer (GBC 932 AA, Victoria, Australia). The biosorption capacity $(Q)$, which is the amount of metallic ion ( $\mathrm{mg}$ ) biosorbed per gram of residual fungal biomass, and the biosorption efficiency $(E)$ were calculated using the following equations (Javaid et al., 2010):

$$
\begin{gathered}
Q=((C i-C f) / m) \times V \\
E=((C i-C f) / C i) \times 100
\end{gathered}
$$

where $C i$ - initial concentration of metallic ions $(\mathrm{mg} / \mathrm{l})$, $C f$ - final concentration of metallic ions $(\mathrm{mg} / \mathrm{l}), m-$ dried mass of the biosorpent in the reaction mixture $(\mathrm{g}), V_{-}$ the volume of the reaction mixture (1).

\section{Statistical analysis}

All data obtained from the experiments (all performed in triplicate) of optimization of biomass and lipid production as well as biosorption of heavy metals were analyzed using analysis of variance (ANOVA). Significant differences among treatments were determined according to the least significant difference (LSD) at $P<0.05$ level of probability by using the CoStat software. The experiments were repeated 3 times.

\section{Results and discussion}

\section{Screening of oleaginous fungi by Nile Red}

Seven fungal isolates were obtained from the collected soil samples. These pure isolates were examined for the lipid production ability by using the Nile Red staining assay. Microscopic examination results indicated that the isolate designated as GAH1 had strong red fluorescence, which implied that it had the most potent lipid accumulation among the fungal isolates as shown in Figure 1 . Therefore, the isolate GAH1 was selected for further investigations.

\section{Identification of the isolate GAH1}

Morphological features demonstrated that the isolated fungal strain GAH1 belongs to Aspergillus fumigatus species. The isolate GAH1 grew rapidly to form cottony colonies on potato dextrose agar at $28^{\circ} \mathrm{C}$. The color of the front side of the colony was white, which progressively changed to greenish gray with age, while the color of the reverse side was white, which became creamy with the maturation of the colony. Microscopic examination of the isolate GAH1 showed that the conidiophores were long and had club-shaped vesicles that were uni-

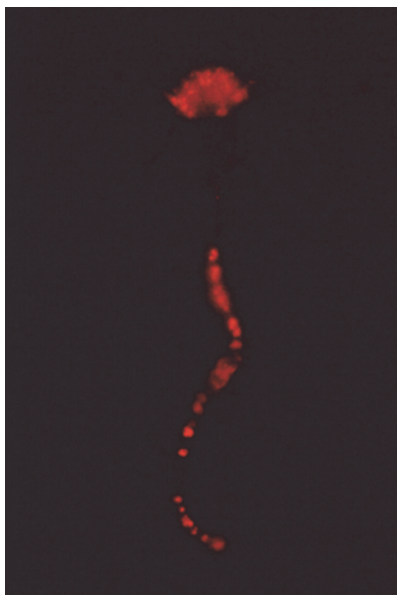

Fig. 1. Nile Red staining of the fungal isolate GAH1 examined by fluorescent microscope; the red fluorescence reflects the lipid granules

seriate and covered by conidia only on the upper half. Conidia arose in chains and tended to sweep toward the central axis as shown in Figure 2. The identification of GAH1 strain was confirmed by repeating the identification procedure in the regional center of mycology, Al-Azhar University, Cairo, Egypt.

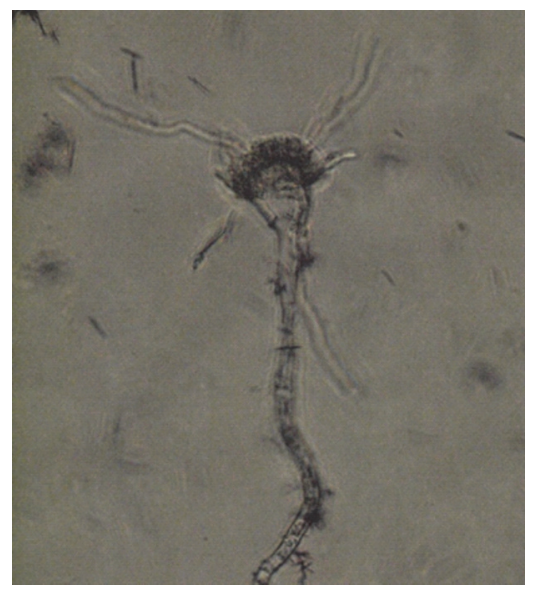

Fig. 2. Mycelium, conidiophore, and conidia of the fungal isolate GAH1 examined by light microscopy

\section{Influence of different carbon sources on the fungal biomass and lipid production}

Different carbon sources such as glucose, sucrose, maltose, and starch were tested. Sucrose was found to support the highest biomass and lipid production with $8.6 \mathrm{~g} / 1$ biomass dry weight and $1.16 \mathrm{~g} / 1$ lipids, respectively, after 6 days of incubation (13.5\% lipid content of the fungal biomass). By using starch and glucose as car- 


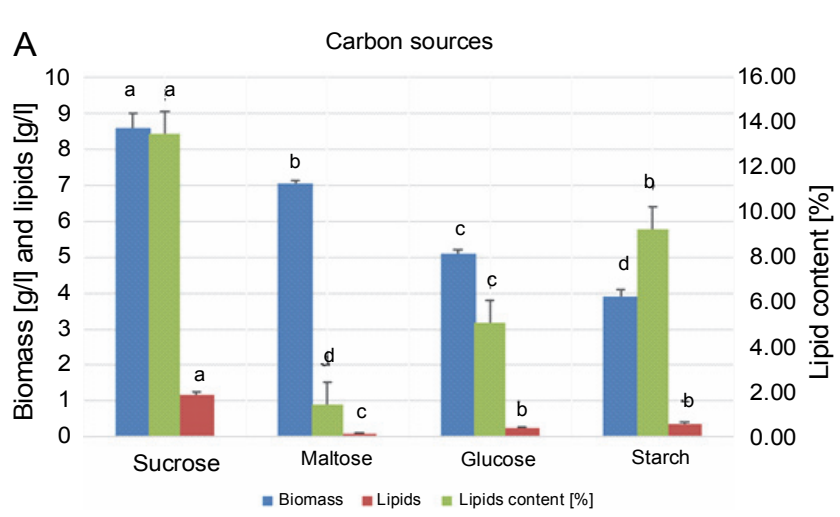

B

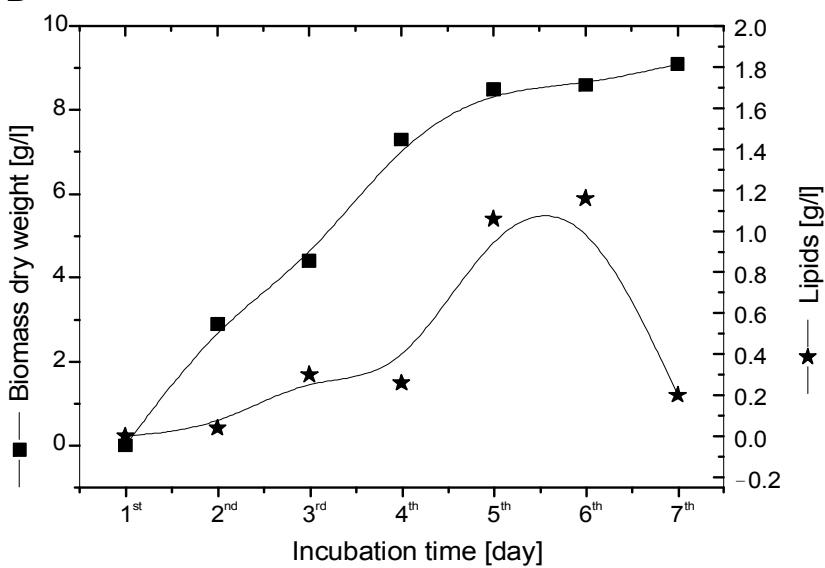

Fig. 3. A) biomass, lipids and lipid content of Aspergillus fumigatus isolate GAH1 growing on different carbon sources for 6 days (values with the identical letters above the bar are not significantly different at $P<0.05$ level); B) biomass and lipid of Aspergillus fumigatus isolate GAH1 growing on sucrose as a carbon source

bon sources, the lipid production and lipid content were $0.36 \mathrm{~g} / 1$ and $9.23 \%$, and $0.26 \mathrm{~g} / 1$ and $5.1 \%$, respectively. Although maltose was the second carbon source supporting biomass production, it was the least lipid-producing carbon source with $0.1 \mathrm{~g} / 1$ lipids after 6 days of incubation (1.42\% lipid content of the fungal biomass) as shown in Figure 3A and Figure 3B. Consequently, sucrose was selected as the best carbon source for lipid production by the $A$. fumigatus GAH1 isolate compared with the other tested carbon sources. This result agrees with the previous report by Papanikolaou et al. (2010) who reported that Thamnidium elegans had the highest total lipid content when sucrose was used as a carbon source compared with glucose and fructose. Similarly, El-Shall et al. (2018) found that sucrose was the best carbon source for lipid production by Alternaria $s p$.

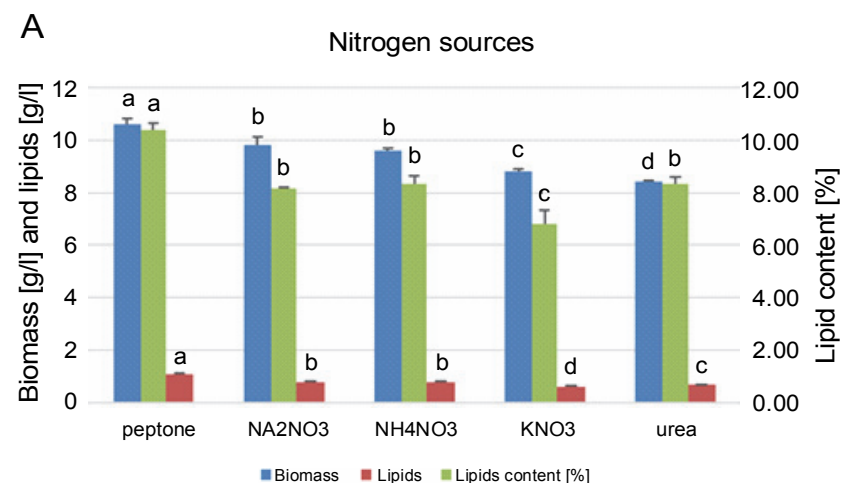

B

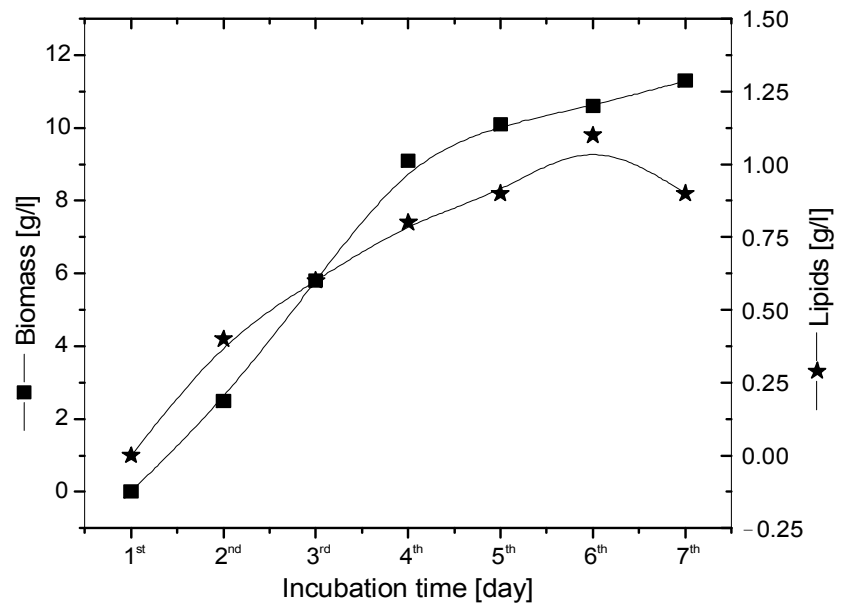

Fig. 4. A) biomass, lipids and lipid content of Aspergillus fumigatus isolate GAH1 growing on different nitrogen sources for 6 days (values with the identical letters above the bar are not significantly different at $P<0.05$ level); B) biomass and lipids of Aspergillus fumigatus isolate GAH1 using peptone as a nitrogen source

\section{Influence of different nitrogen sources on fungal biomass and lipid production}

Different nitrogen sources such as peptone, sodium nitrate, ammonium nitrate, potassium nitrate, and urea were investigated. The highest lipid production was observed when peptone was used as a nitrogen source, with $1.1 \mathrm{~g} / 1$ lipids and $10.4 \%$ lipid content of the fungal biomass after 6 days of incubation. On the other hand, lipid production was the lowest when potassium nitrate was used, with $0.6 \mathrm{~g} / \mathrm{l}$ lipids and $6.82 \%$ lipid content of the fungal biomass. Moreover, when sodium nitrate and ammonium nitrate were used as nitrogen sources, the lipid production and lipid content were $0.8 \mathrm{~g} / 1$ lipids and $8.16 \%$, and $0.8 \mathrm{~g} / 1$ lipids and $8.33 \%$, respectively, with no significant difference. The lipid production and lipid content were $0.7 \mathrm{~g} / 1$ lipids and $8.33 \%$ when urea was 


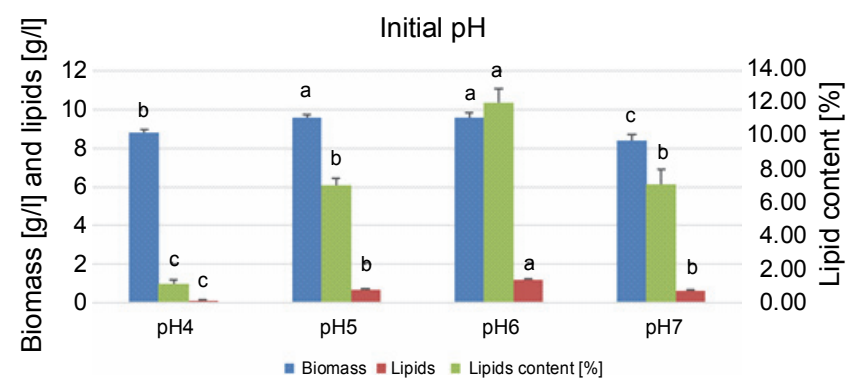

Fig. 5. Biomass, lipids and lipid content of Aspergillus fumigatus isolate $\mathrm{GAH} 1$ growing on different $\mathrm{pH}$ values for 6 days; values with the identical letters above the bar are not significantly different at $P<0.05$ level

used as a nitrogen source. Peptone supported not only lipid production but also the highest biomass production, with $10.6 \mathrm{~g} / 1$ fungal biomass dry weight as shown in Figure 4A and Figure 4B. On the basis of these results, peptone was designated as the best nitrogen source for both lipid accumulation and biomass production. Similarly, it has been reported that peptone as an organic nitrogen source enhanced biomass and oil production by Tolyposporium ehrenbergii, Sphacelotheca reiliana, Lipomyces starkeyi, and Tricosporon fermentans (Farag et al., 1983; Zhu et al., 2008; Azad et al., 2014). Inorganic nitrogen sources such as ammonium nitrate and potassium nitrate were found to be favorable for lipid accumulation during the cultivation of Cunninghamella japonica and Aspergillus versicolor, respectively (Lunin et al., 2013; Karatay and Doenmez, 2014).

\section{Influence of initial pH on the fungal biomass and lipid production}

$\mathrm{pH}$ is one of the most important parameters affecting cell growth and lipid production by microorganisms (Amanullah et al., 2001; Hong et al., 2006). In the current study, biomass and lipid production by $A$. fumigatus GAH1 were examined at different $\mathrm{pH}$ values ranging from 4.0 to 7.0. When the fungus grew at $\mathrm{pH} 4.0$, the fungal biomass, lipids, and lipid contents of the fungal biomass were $8.8 \mathrm{~g} / 1,0.1 \mathrm{~g} / \mathrm{l}$, and $1.14 \%$, respectively. When the fungus grew at $\mathrm{pH} 5.0$, the fungal biomass, lipids, and lipid contents of the fungal biomass were $9.6 \mathrm{~g} / \mathrm{l}, 0.68 \mathrm{~g} / \mathrm{l}$, and $7.08 \%$, respectively. Furthermore, when the fungus grew at $\mathrm{pH} 6.0$, the fungal biomass, lipids, and lipid contents of the fungal biomass were $9.6 \mathrm{~g} / 1,1.16 \mathrm{~g} / \mathrm{l}$, and $12.08 \%$, respectively. Moreover, when the fungus grew at $\mathrm{pH} 7.0$, the fungal biomass, lipids, and lipid contents of the fungal biomass were $8.4 \mathrm{~g} / \mathrm{l}, 0.6 \mathrm{~g} / \mathrm{l}$, and $7.14 \%$, respectively, as shown in Figure 5 . From these results, it is clear that $A$. fumigatus GAH1 produced the highest biomass and lipids at $\mathrm{pH}$ 6.0, because the maximum biomass $9.6 \mathrm{~g} / 1$ (dry weight) and lipids $1.16 \mathrm{~g} / 1$ were achieved when the fungus was grown on the medium adjusted to $\mathrm{pH} 6.0$ and the lipid content of the fungal biomass was $12.08 \%$. Therefore, $\mathrm{pH} 6.0$ was considered as the best tested $\mathrm{pH}$ for biomass and lipid production. The results also indicated that there was no difference in the average biomass accumulation at $\mathrm{pH} 5.0$ and 6.0; however, lipid production was significantly different between the two treatments. On the other hand, at $\mathrm{pH} 4.0$, lipid production was minimal despite the normal fungal biomass production. These results support the importance of $\mathrm{pH}$ as a limiting factor for fungal lipid production. These results also agree with the recent findings that $\mathrm{pH} 6.0$ was the most suitable $\mathrm{pH}$ for arachidonic acid and biomass production by Mortierella alpine (Mironov et al., 2018). It was also reported that the initial pH 5.5 is the most suitable for lipid production by Rhodotorula glutinis, Cutaneotrichosporon curvatus, and Rhodotorula toruloides (Tao et al., 2008; El-Fadaly et al., 2009; Kraisintu et al., 2010). On the other hand, it has been shown that the maximum lipid accumulation by Lipomyces starkeyi was obtained at $\mathrm{pH} 5.0$, while the highest biomass was obtained at pH 6.5 (Angerbauer et al., 2008).

\section{Cultivation of A. fumigatus AGH1 under the optimized conditions}

According to the above results of OVAT optimization, the $A$. fumigatus AGH1 isolate was grown on the optimized Czapek-Dox medium (sucrose as a carbon source, peptone as a nitrogen source, and the initial $\mathrm{pH}$ adjusted to $\mathrm{pH}$ 6.0). The maximum lipid production was achieved when the fungus grew on the optimized medium for 5 days with lipid yield of $2.45 \mathrm{~g} / \mathrm{l}$ and $22.4 \%$ lipid content of the fungal biomass. Increasing the incubation time to 6 or even 7 days enhanced the fungal biomass production to 11.63 and $12.24 \mathrm{~g} / 1$, respectively, but the lipid accumulation was reduced to $1.71 \mathrm{~g} / 1$, and $14.7 \%$ lipid content of the fungal biomass, and $1.9 \mathrm{~g} / \mathrm{l}$, and $15.5 \%$ lipid content of fungal biomass, respectively, with no significant difference between day 6 and day 7 , as shown in Figure 6A and Figure 6B. These results show that the A. fumigatus GAH1 isolate can be considered as a pro- 
A Biomass, lilpid and lipid content of A. fumigatus GAH1 growing on optimized medium

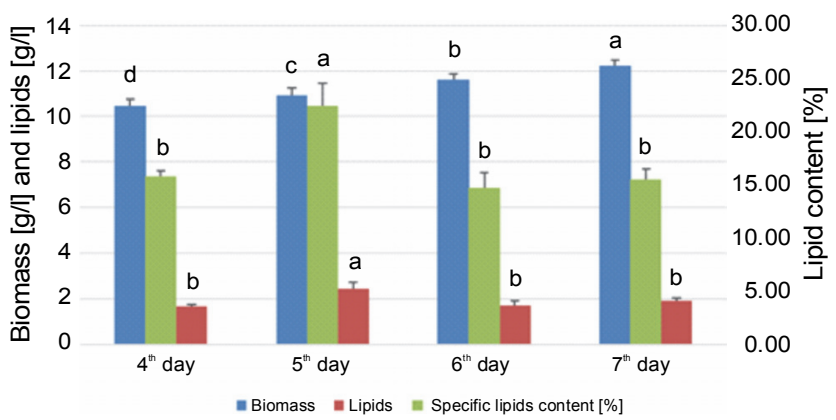

B

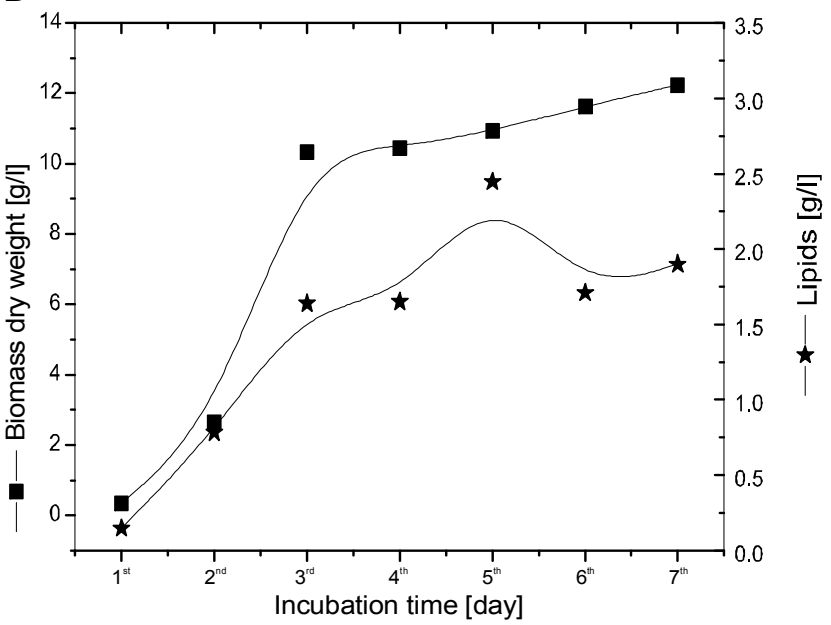

Fig. 6. A) biomass, lipids and lipid content of Aspergillus fumigatus isolate GAH1 growing on optimized medium (values with the identical letters above the bar are not significantly different at $P<0.05$ level); B) biomass and total lipids content of $A s^{-}$ pergillus fumigatus GAH1 isolate grown on optimized medium

mising oleaginous fungus because it accumulated $22.4 \%$ of its biomass dry weight as lipids, and hence, it might be used for biodiesel production. The optimization results are consistent with the report of Subhash and Mohan (2011) who found that on Sabouraud dextrose broth medium, Aspergillus sp. produced $13.6 \mathrm{~g} / \mathrm{l}$ biomass dry weight and $23.3 \%$ lipid content of its fungal biomass.

\section{Fatty acid profile analysis}

The composition of fatty acids of the A. fumigatus GAH1 isolate, grown on the optimized medium, was analyzed by GC/MS. The fungal lipids were found to contain saturated $(45.1 \%)$, monounsaturated $(39.67 \%)$, and polyunsaturated (15.15\%) fatty acids. Oleic (C18:1) and palmitic (C16:0) acids were the dominant fatty acids produced by $A$. fumigatus GAH1 with the yield of $49.37 \mathrm{mg} / \mathrm{g}$ and $42.012 \mathrm{mg} / \mathrm{g}$, respectively, followed by linolenic $(\mathrm{C} 18: 3)$ and stearic $(\mathrm{C} 18: 0)$ acids, with the yield of
$18.59 \mathrm{mg} / \mathrm{g}$ and 12.96 , respectively. Other fatty acids such as octanoic (C8:0), lauric (C12:0), myristic (C14:0), linoleic (C18:2), arachidic (C20:0), and behenic (C22:0) were also present, but in amounts lesser than $1 \mathrm{mg} / \mathrm{g}$, as shown in Table 1 . As reported previously, the FAME produced from the fungal lipids contained long chain saturated and unsaturated fatty acids with a higher number of saturated fatty acids; hence, it had the capability of acquiring high fuel and lubricating properties (Amin, 2009; Demirbas, 2010). Accordingly, the obtained results suggested that the lipids of the oleaginous fungus $A$. fumigatus GAH1 isolate could be used as a potential feedstock for biodiesel production.

\section{Fungal biomass waste as a biosorbent for the removal of heavy metals}

Biosorption of heavy metals by microbial biomass has been known as a potential alternative to existing technologies for bioremediation of heavy metals from industrial wastewater. In this work, the residual fungal biomass resulting from the lipid extraction was evaluated for the biosorption of chromium, cadmium, and zinc in artificial wastewater. The residual fungal biomass was applied as untreated, $\mathrm{H}_{2} \mathrm{O}$-washed, and $\mathrm{NaOH}$-treated biomasses. As shown in Figure 7, the results indicated that the maximum biosorption of heavy metals by the residual fungal biomass was achieved when the biomass was pretreated with $\mathrm{NaOH}$, where the biosorption efficiency and biosorption capacity were $83.43 \%$ and $33.37 \mathrm{mg}$ heavy metal $\mathrm{g}_{\text {biomass }}, 73 \%$ and $29.29 \mathrm{mg} / \mathrm{g}$, and $27.75 \%$ and $69.39 \mathrm{mg} / \mathrm{g}$ for chromium, cadmium, and zinc, respectively. Biosorption efficiency and capacity of $\mathrm{H}_{2} \mathrm{O}$-washed fungal biomass were $75.89 \%$ and $30.35 \mathrm{mg} / \mathrm{g}$ for chromium, $27 \%$ and $10.81 \mathrm{mg} / \mathrm{g}$ for cadmium, and $48.65 \%$ and $19.42 \mathrm{mg} / \mathrm{g}$ for zinc. The lowest biosorption efficiency and biosorption capacity were obtained when the fungal biomass was used directly without any treatment, where biosorption efficiency and capacity of $71.47 \%$ and $28.58 \mathrm{mg} / \mathrm{g}, 15.7 \%$ and $6.31 \mathrm{mg} / \mathrm{g}$, and $52.91 \%$ and $21.16 \mathrm{mg} / \mathrm{g}$ were recorded for chromium, cadmium, and zinc, respectively. There was, however, no significant difference in biosorption efficiency and capacity between untreated and $\mathrm{H}_{2} \mathrm{O}$-washed fungal biomass for both chromium and zinc. Previously, it was reported that Aspergillus niger biomass showed $84 \%$ removal of cadmium ions and $55 \%$ removal of zinc ions (Luef et al., 1991; Barros et al., 2003; Congeevaram et al., 2007). Moreover, filamentous fungi 
Table 1. Fatty acids composition of lipid extracted from $A$. fumigatus GAH1 grown in optimized medium

\begin{tabular}{|c|c|c|}
\hline Fatty acid & $\begin{array}{c}\text { Concentration } \\
{[\mathrm{mg} / \mathrm{g}]}\end{array}$ & $\begin{array}{c}\text { Concentration } \% \\
\text { (fatty acid to the total fatty acids) }\end{array}$ \\
\hline Octanoate $(\mathrm{C} 8: 0)$ & 0.020 & 0.02 \\
\hline Laurate (C12:0) & 0.011 & 0.01 \\
\hline Myristate (C14:0) & 0.608 & 0.49 \\
\hline Palmitate $(\mathrm{C} 16: 0)$ & 42.012 & 33.76 \\
\hline Stearate $(\mathrm{C} 18: 0)$ & 12.96 & 10.41 \\
\hline Oleate $(\mathrm{C} 18: 1)$ & 49.37 & 39.67 \\
\hline Linolenate (C18:3) & 18.588 & 14.94 \\
\hline Linoleate $(\mathrm{C} 18: 2)$ & 0.266 & 0.21 \\
\hline Arachidate $(\mathrm{C} 20: 0)$ & 0.228 & 0.18 \\
\hline Behenate (C22:0) & 0.412 & 0.33 \\
\hline $\begin{array}{l}\text { Total saturated } \\
\text { Total monounsaturated } \\
\text { Total polyunsaturated }\end{array}$ & & $\begin{array}{c}45.1 \% \\
39.67 \% \\
15.15 \%\end{array}$ \\
\hline
\end{tabular}

A

$$
\begin{array}{r}
100 \\
90 \\
80 \\
70 \\
60 \\
50 \\
40 \\
30 \\
20 \\
10 \\
0
\end{array}
$$

Biosorption of $\mathrm{Cr}$ on $A$. fumigatus residual biomass
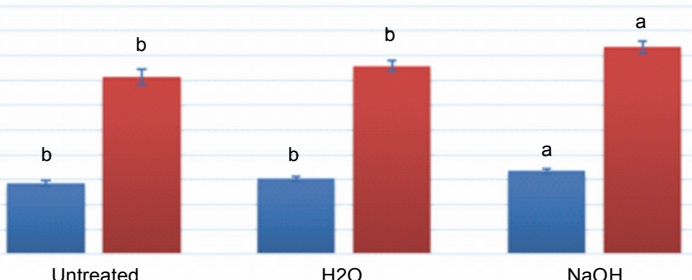

= Biosorption capacity $Q[\mathrm{mg} / \mathrm{g}$

- Biosorption efficiency $\mathrm{E}[\%]$

B

Biosorption of $\mathrm{Cd}$ on $A$. fumigatus residual biomass

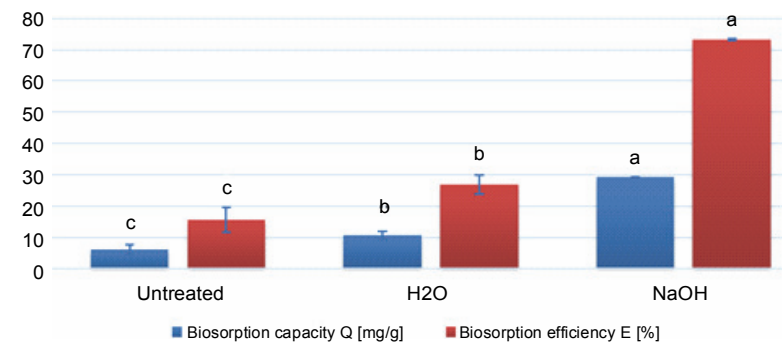

C

Biosorption of $\mathrm{Zn}$ on A. fumigatus residual biomass

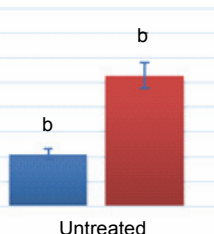

Untreated

- Biosorption capacity $\mathrm{Q}[\mathrm{mg} / \mathrm{g}$

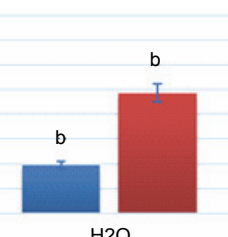

- Biosorption efficiency $\mathrm{E}[\%]$
Fig. 7. Biosorption of $\mathrm{Cd}(\mathrm{A}), \mathrm{Cr}(\mathrm{B})$, and $\mathrm{Zn}(\mathrm{C})$ on A. fumigatus $\mathrm{GAH} 1$ residual biomass untreated, $\mathrm{H}_{2} \mathrm{O}$ washed, and treated with $\mathrm{NaOH}$ (values with the identical letters above the bar are not significantly different at $P<0.05$ level) such as A. niger, Penicillium chrysogenum, and Claoiceps paspali have been shown to remove zinc with the removal capacity of $55 \%, 8 \%$, and $12 \%$, respectively (Luef et al., 1991). Pleurotus ostreatus has been reported to remove $85 \%$ of cadmium ions (Tay et al., 2013). Other researchers have reported the ability of some bacteria and fungi to remove $\mathrm{Ni}$ and $\mathrm{Cr}$ with high efficiency (Beopoulos et al., 2008; Subhash and Mohan 2011). Hence, the use of the residual fungal biomass as a biosorbent could be helpful in bioremediation of heavy metal-contaminated environments.

The primary goal of this work was to optimize the production of lipids from the $A$. fumigatus GAH1 isolate, and the secondary goal was to study the potential use of the resultant fungal debris as a natural heavy metal sorbent material. However, there were some limitations to investigate this secondary goal, because many factors could affect the heavy metal removal efficiency, such as initial concentration of the heavy metals, $\mathrm{pH}$, temperature, the amount of adsorbent dose, and time of exposure (Gupta and Rostagi, 2008; Mojoudi et al., 2019). Moreover, it was previously reported that the efficiency of heavy metal removal was found to be affected by the initial concentration of the tested heavy metals. For example, Mojoudi et al. (2019) reported a gradual reduction in heavy metal removal percentage from $91 \%$ to $65 \%$ when the initial concentration $\mathrm{Pb}$ (II) increased from $50 \mathrm{ppm}$ to $120 \mathrm{ppm}$, respectively. Similarly, Berhe et al. 
(2015) reported a reduction in the removal efficiency of $\mathrm{Pb}$ (II) from polluted effluents by using Ethiopian coffee husk. Because we used $100 \mathrm{ppm}$ of $\mathrm{Zn}, \mathrm{Cd}$, and $\mathrm{Cr}$ as the initial concentration for the sorption experiment based on our previous studies and none of the other factors affecting the heavy metal removal efficiency were optimized, the need for an optimization experiment is highly recommended to achieve the best heavy metal removal efficiency using the residual fungal debris.

\section{Conclusions}

Aspergillus fumigatus GAH1 isolate was the most efficient fungal isolate for lipid accumulation $(>20 \%)$ among the several isolated filamentous fungi. Optimal conditions for maximum lipid production were evaluated. Lipid content of $22.4 \%$ was achieved on the fifth day of growth in optimized Czapek-Dox liquid medium using sucrose as a carbon source and peptone as a nitrogen source, with initial pH 6.0. GC-MS study revealed that the fatty acids oleic, palmitic, linolenic, and stearic were predominant in the lipid sample; hence, the fungal lipids may be used as a potential feedstock for biodiesel production. The use of fungal biomass waste as a biosorbent to remove heavy metals from contaminated wastewater had a competitive advantage for the production of lipid by the isolated fungal strain. In fact, the residual fungal biomass, especially after treatment with $0.5 \mathrm{~N} \mathrm{NaOH}$ for 15 min, could remove $\mathrm{Cr}, \mathrm{Cd}$, and $\mathrm{Zn}$ with the absorption efficiency of $83.43 \%, 73 \%$, and $69.39 \%$, respectively.

\section{References}

Abu-Elreesh G.M., Abd-El-Haleem D.A. (2014) Biodiesel, bioflocculant, and biosorbent from the fungal Curvularia sp. strain DFH. Eur. J. Exp. Biol. 4(1): 218-226.

Akhtar M., Sastry K., Mohan P. (1996) Mechanism of metal ion biosorption by fungal biomass. Biometals 9: 21-28.

Amanullah A., McFarlane C.M., Emery A.N., Nienow A.W. (2001) Scale-down model to simulate spatial $p H$ variations in large-scale bioreactors. Biotechnol. Bioeng. 73: 390-399.

Amin S. (2009) Review on biofuel oil and gas production processes from microalgae. Energy Conv. Manag. 50: 1834-1840.

Angerbauer C., Siebenhofer M. et al. (2008) Conversion of sewage sludge into lipids by Lipomyces starkeyi for biodiesel production. Bioresour. Technol. 99: 3051-3056.

Azad A.K., Yousuf A., Ferdoush A., Mahbub Hasan M.D., Rezaul Karim M.D. et al. (2014) Production of microbial lipids from rice straw hydrolysates by Lipomyces starkeyi for biodiesel synthesis. J. Microb. Biochem. Technol. S8: 008. DOI: http://doi.org/10.4172/1948-5948.S8-008.
Barros L., Macedo G., Duarte M., Silva E., Lobato A.K.C.L. (2003) Biosorption of Cadmium using the fungus Aspergillus niger. Braz. J. Chem. Eng. 20: 229-239.

Beopoulos A., Mrozova Z., Thevenieau F., Le Dall M.T., Hapala I., Papanikolaou S., Chardot T., Nicaud J.M. (2008) Control of lipid accumulation in the yeast Yarrowia lipolytica. Appl. Environ. Microbiol. 74: 7779-7789.

Bligh E.G., Dyer W.J. (1959) A rapid method of total lipid extraction and purification. Can. J. Biochem. Physiol. 37(8): 911-917.

Berhe S., Ayele D., Tadesse A., Mulu A. (2015) Adsorption efficiency of coffee husk for removal of lead (II) from industrial effluents: equilibrium and kinetic study. Int. J. Sci. Res. Pub. 5: 1-8.

Cheirsilp B., Kitcha S. (2015) Solid state fermentation by cellulolytic oleaginous fungi for direct conversion of lignocellulosic biomass into lipids: fed-batch and repeated-batch fermentations. Ind. Crops Prod. 66: 73-80.

Chi Z., Pyle D., Wen Z., Frear C., Chen S. (2007) A laboratory study of producing docosahexaenoic acid from biodieselwaste glycerol by microalgal fermentation. Proc. Biochem. 42: 1537-1545.

Congeevaram S., Dhanarani S., Park J., Dexilin M., Thamaraiselvi K. (2007) Biosorption of chromium and nickel by heavy metal resistant fungal and bacterial isolates. Hazard Mater 146: 270-277.

Costa A.C.A., Leite S.G.C. (1991) Metal biosorption by sodium alginate immobilized Chlorella homosphaera. Biotechnol. Lett. 13: 559-562.

Demirbas A. (2010) Use of algae as biofuel sources. Energy Conv. Manag. 51: 2738-2749.

El-Shall H., Abu-Elreesh G., El-Sabbagh S., Haddad A., Abd-ElHaleem D. (2018) Single cell oil production by Alternaria sp. using molasses as a substrate. Int. J. Recent Sci. Res. 9(8): 28324-28335.

El-Fadaly H.A., El-Naggar N.A., Marwan S.M. (2009) Single cell oil production by an oleaginous yeast strain in a low cultivation medium. Res. J. Microbiol. 4: 301-313.

Farag R.S., Khalil F.A., Salem H., Ali L.H.M. (1983) Effects of various carbon and nitrogen sources on fungal lipid production. J. Amer. Oil Chem. Soc. 60(4): 795-800.

Greenspan P., Mayer E.P., Fowler S.D. (1985) Nile red: a selective fluorescent stain for intracellular lipid droplets. J. Cell Biol. 100(3): 965-973.

Gupta V.K., Rastogi A. (2008) Sorption and desorption studies of chromium (VI) from nonviable cyanobacterium Nostoc muscorum biomass. J. Hazard. Mater. 154: 347-354.

Hamidian A.H., Zareh Reshqueih M., Poorbagher H., Vaziri L., Ashrafi S. (2016) Heavy metal bioaccumulation in sediment, common reed, algae and blood worm from the Shoor River, Iran. J. Toxicol. Ind. Health 32(3): 398-409.

Hong L.Y., Bo L., Bao Z.Z., Wu B.F. (2006) Optimization of culture conditions for lipid production by Rhodosporidium toruloides. Chin. J. Biotech. 22: 650-656.

Hui L., Wan C., Hai-tao D., Xue-jiao C., Qi-fa Z., Yu-hua Z. (2010) Direct microbial conversion of wheat straw into lipid by 
a cellulolytic fungus of Aspergillus oryzae A-4 in solid-state fermentation. Bioresour. Technol. 101: 7556-7562.

Hussein H., Ibrahim S.F., Kandeel K., Moawad H. (2004) Biosorption of heavy metals from wastewater using Pseudomonas sp. Electronic J. Biotechnol. 7: 38-42.

Javaid A., Bajwa R., Javaid A. (2010) Biosorption of heavy metals using a dead macrofungus Schizophllum commune fries: Evaluation of equilibrium and kinetic models. Pak. J. Bot. 43: 419-425.

Kahr H., Pointner M., Krennhuber K., Wallner B., Jäger A. (2015) Lipid production from diverse oleaginous yeasts from steam-exploded corn cobs. Agronomy Res. 13(2): $318-327$.

Karatay S.E., Dönmez G. (2014) Evaluation of biotechnological potentials of some industrial fungi in economical lipid accumulation and biofuel production as a field of use. Prep. Biochem. Biotechnol. 44: 332-334.

Kidd S., Halliday C., Alexiou H., Ellis D. (2016) Description of medical fungi $\left(3^{\text {rd }}\right.$ ed.) Newstyle Printing, Adelade, South Australia.

Kimura K., Yamaoka M., Kamisaka Y. (2004) Rapid estimation of lipids in oleaginous fungi and yeasts using Nile red fluorescence. J. Microbiol. Meth. 56: 331-338.

Kraisintu P., Yongmanitchai W., Limtong S. (2010) Selection and optimization for lipid production of a newly isolated oleaginous yeast, Rhodosporidium toruloides DMKU3TK16. Kasetsart J. (Nat. Sci.) 44: 436-445.

Kulkarni M.G., Dalai A.K. (2006) Waste cooking oils - an economical source for biodiesel: a review. Ind. Eng. Chem. Res. 45: 2901-2913.

Li Q., Du W., Liu D. (2008) Perspectives of microbial oils for biodiesel production. Appl. Microbiol. Biotech. 80: 749-756.

Li P., Miao X., Li R., Zhong J. (2011) In situ biodiesel production from fast-growing and high oil content Chlorella pyrenoidosa in rice straw hydrolysate. J. Biomed. Biotech. 2011: 8 .

Liang M.H., Jiang J.G. (2013) Advancing oleaginous microorganisms to produce lipid via metabolic engineering technology. Progr. Lipid Res. 52: 395-408.

Lunin V.V., Sergeev I.E., Galanina L.A. et al. (2013) Biodiesel fuel production from lipids of filamentous fungi. Appl. Biochem. Biotechnol. 49: 46-52.

Meng X., Yang J.M., Xu X., Zhang L., Ni Q.J., Xian M. (2009) Biodiesel production from oleaginous microorganisms. Renew. Energy 34: 1-5.

Mironov A.A., Nemashkalov V.A., Stepanova N.N., Kamzolova S.V., Rymowicz W., Morgunov I.G. (2018) The effect of $p H$ and temperature on arachidonic acid production by glycerol-grown Mortierella alpina NRRL-A-10995. Fermentation 4: 17.

Mohsenzadeh F., Shahrokhi F. (2014) Biological removing of Cadmium from contaminated media by fungal biomass of Trichoderma species. J. Environ. Health Sci. Eng. 12: 102.

Mojoudi F., Hamidian A.H., Zhang Y., Yang M. (2019) Synthesis and evaluation of Activated Carbon/Nanoclay/ Thiolated Graphene Oxide Nanocomposite for Lead (II) Remo- val from Aqueous Solution. Water Sci. Technol. 79(3): 466-479.

Mudhoo A., Garg V.K., Wang S. (2012) Removal of heavy metals by biosorption. Environ. Chem. Lett. 10: 109-117.

Muniraj I.K., Xiao L., Hu Z., Zhan X., Shi J. (2013) Microbial lipid production from potato processing wastewater using oleaginous filamentous fungi Aspergillus oryzae. Water Res. 47: 3477-3483.

Papanikolaou S., Diamantopoulou P., Chatzifragkou A. et al. (2010) Suitability of low-cost sugars as substrates for lipid production by the fungus Thamnidium elegans. Energ. Fuel 24(7): 4078-4086.

Ratledge C., Cohen Z. (2013) Microbial and algal oils: do they have a future for biodiesel or as commodity oils. Lipid Technol. 20: 155-160.

Rawat I., Ranjith K.R., Mutanda T., Bux F. (2013) Review on biofuel oil and gas production processes from microalgae. Appl. Energy 103: 444-467.

Samson R.A., Hong S., Peterson S.W., Frisvad J.C., Varga J. (2007) Polyphasic taxonomy of Aspergillus section Fumigati and its teleomorph Neosartorya. Stud. Mycol. 59: 147-203.

Simonescu C.M., Ferdes M. (2012) Fungal biomass for Cu (II) uptake from aqueous systems. Pol. J. Environ. Stud. 6: 1831-1839.

Singh A., Nigam P.S., Murphy J.D. (2011) Mechanism and challenges in commercialization of algal biofuels. Bioresour. Technol. 102: 26-34.

Subhash G.V., Mohan S.V. (2011) Biodiesel production from isolated oleaginous fungi Aspergillus sp. using corncob waste liquor as a substrate. Bioresour. Technol. 102: 9286-9290.

Tao J., Dai C., Li R., Chen J., Zhang B. (2008) The changes of micro diesel composition with the culture conditions by fallen leaves of Populus euramevicana $c v$. Int. J. Sustain Energ. 27: 73-79.

Tay C.C., Abdullah-Suhaimi A., Liew H.H. (2013) Fungal Pleurotus ostreatus biosorbent for Cadmium (II) removal in industrial wastewater. J. Life Sci. Technol. 1: 1.

Vala A.K., Sutariya V. (2012) Trivalent Arsenic tolerance and accumulation in two facultative marine fungi. Joundishapur J. Microbiol. 5: 542-545.

Vankar P.S., Bajpai D. (2008) Phyto-remediation of Chrome-VI of tannery effluent by Trichoderma species. Desalination 222: 255-262.

Vicente G.L., Bautista F., Rodriguez R.F., Gutierrez J., Sadaba I., Ruiz-Vazquez R.M., Torres-Martinez S., Garre V. (2009) Biodiesel production from biomass of an oleaginous fungus. Biochem. Eng. J. 48: 22-27.

Yi S.J., Zheng Y.P. (2006) Research and application of oleaginous microorganism. China Foreign Energy 11: 90-94.

Zhu L.Y., Zong M.H., Wu H. (2008) Efficient lipid production with Trichosporon fermentans and its use for biodiesel preparation. Bioresour. Technol. 99: 7881-7885. 